\title{
Unique relationship between osteophyte and femoral-tibia component size mismatch in determining polyethylene wear in primary total knee arthroplasty: a case report Manjunath Ramappa* and Andrew Port
}

Address: James Cook University Hospital, Middlesbrough, UK

Email: Manjunath Ramappa* - drbrm2004@yahoo.co.uk; Andrew Port - andrew.port@stees.nhs.uk

* Corresponding author

Published: 10 February 2009

Received: 12 August 2008

Journal of Medical Case Reports 2009, 3:59 doi:10.1 186/1752-1947-3-59

Accepted: 10 February 2009

This article is available from: http://www.jmedicalcasereports.com/content/3/1/59

(c) 2009 Ramappa and Port; licensee BioMed Central Ltd.

This is an Open Access article distributed under the terms of the Creative Commons Attribution License (http://creativecommons.org/licenses/by/2.0),

which permits unrestricted use, distribution, and reproduction in any medium, provided the original work is properly cited.

\begin{abstract}
Introduction: Knee pain is a complex problem that can occur after total knee arthroplasty. One cause of knee pain may be due to a retained osteophyte, but it is not clear if the retained osteophyte is sufficient explanation of the pain, as not all patients with retained osteophytes are symptomatic. In fact, the literature shows that excised osteophytes can also recur over a period of time, without any symptoms. Therefore a retained osteophyte alone is probably not sufficient to cause symptoms.
\end{abstract}

Case presentation: We present a case of intermittent medial knee pain occurring post-primary total knee arthroplasty, in a patient who underwent several investigations over a period of 5 years. Radiographs showed an osteophyte in the postero-medial femur along with slight tibial component overhang which was normal for that knee implant design. The symptoms eventually settled with excision of only the osteophyte, without altering the tibial component.

Conclusion: A retained osteophyte alone, or tibial component overhang alone, did not seem to cause significant symptoms in our patient whose symptoms completely settled with excision of the osteophyte alone, without changing the tibial component. Therefore, it seems that the combination of retained osteophyte and tibial component overhang (tibia-femoral component size mismatch) are detrimental and therefore best avoided. This report also emphasises the importance of meticulous osteophyte excision and avoiding tibial component overhang during knee arthroplasty.

\section{Introduction}

This case report discusses knee-implant designs which have natural femoral-tibial component mismatch with tibial component overhang, and their unique association with the surrounding soft tissues, especially retained osteophytes. To our knowledge, this relationship has never been described before.
Total knee arthroplasty (TKA) is an effective means of providing pain relief for patients with arthritic knees. There appears to be rapid and substantial improvement in the patient's pain, functional status and overall health-related quality of life in about $90 \%$ of cases. However, in a few patients, pain persists even after arthroplasty. Successful treatment of this pain depends on the cause [1]. If the 
cause is a rarity, it becomes a diagnostic as well as therapeutic challenge.

Pain can have a mechanical origin, when it is caused by loosening or component failure, or it can be continous when associated with infection. Delayed-onset pain is usually associated with infection or inflammation (synovitis, tendonitis, wear process) [2].

Variables that affect the wear of a polyethylene bearing in vivo include the following: wear resistance of the materials as well as the loads, lubrication, sliding distance, motion pattern, specifics of the design and manufacturing of the polyethylene component, implantation techniques, type of wear and amount and type of use of the joint.

We know that component-size mismatch can contribute to instability after TKA [3]. The component-size mismatch, however, can be normal for some knee implant designs. Also, the mismatch can expose more surface area of that non-articulating polyethylene to surrounding tissues.

\section{Case presentation}

A 64-year-old man had undergone right TKA for osteoarthritis, with a cruciate-retaining PFC knee system: size 5 femur and 5 tibia with a $10 \mathrm{~mm}$ posterior lipped tibial insert. The initial postoperative period was uneventful with 0 to 100 degrees of knee flexion. The X-ray (Figure 1) showed good knee alignment with a slight tibial overhang. An untrimmed osteophyte was identified at the postero-medial femoral condyle. In the first follow-up at 6 weeks, the patient complained of minimal pain and swelling at the anteromedial aspect of the knee. His symptoms progressed and, at 6 months, the patient underwent an arthroscopic exploration with washout and samples were sent for culture \& sensitivity. All samples were negative for any microorganisms. C-reactive protein, white-cell count and erythrocyte sedimentation rate remained stable and the pain appeared to settle. At 1-year follow up, the patient had some medial knee pain which was controllable. At this stage, he seemed pleased with the outcome of the surgery. At 3 years, he presented at the clinic again due to recurrence of medial knee pain. X-rays showed no changes. Technetium $99 \mathrm{~m}$ diphosphonate bone scintigraphy showed increased uptake on the delayed phase mainly in the medial femoral and tibial condyle, which was inconclusive. Inflammatory markers were again stable. The pain disappeared shortly after the scan. The pain recurred once again 5 years after surgery and examination revealed a tender point at the medial joint line with a palpable lump and good range of flexion. No changes were observed on a repeat X-ray (Figure 2). At this stage, the medial joint line was explored which showed a small osteophyte at the postero-medial border of the femur, causing

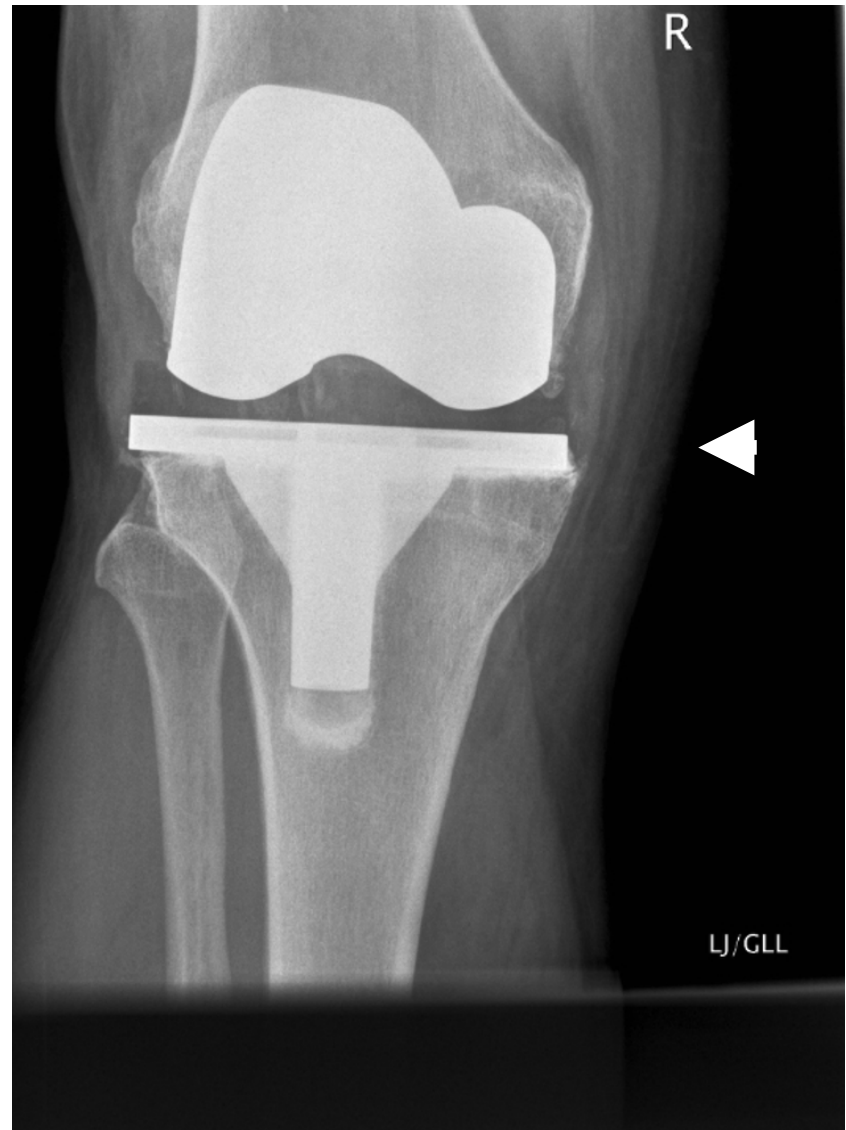

Figure I

Initial post-total knee arthroplastyradiograph, showing medial femoral osteophyte (arrow) and tibial component overhang compared to the femoral component.

a localised polyethylene rim wear (non-articulating part) and localised medial synovial reaction. The osteophyte was excised. Tibial and femoral components were stable and hence not revised. At 2 years post-osteophyte excision (Figure 3), the patient was pain-free and asymptomatic. Throughout this period, the patient had good knee alignment with 0 to 100 degrees of flexion.

\section{Discussion}

Intermittent knee pain following arthroplasty poses a significant therapeutic challenge. Arthroscopy has a limited role post-TKA [4]. The clinical triad of effusion, pain and progressive change in the alignment of the knee which is characteristic of accelerated polyethylene wear [5] is not always seen. Some causes of pain reported in the literature after total knee replacement include remnant soft tissues $[6,7]$, polyethylene wear, low-grade infection, loosening, malalignment and over-stuffing. The intermittent exacerbation of symptoms is secondary to intermittent synovitis [8]. A conservative approach and reassurance has had suc- 


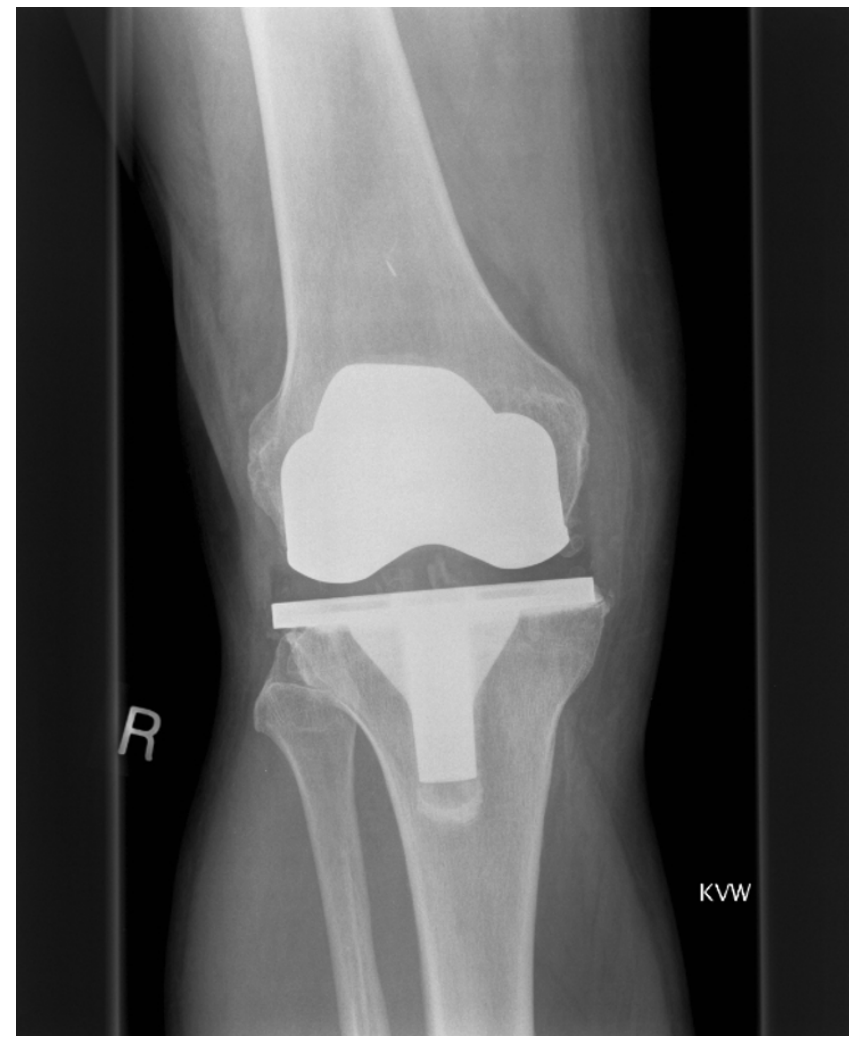

Figure 2

Radiograph at 5 years post-total knee arthroplasty, with medial femoral osteophyte (arrow) and tibial component overhang compared to femoral component.

cess in the management of undiagnosed knee pain in the past [1].

'Wear' is the removal of material as a result of the relative motion between two opposing surfaces under load. Wear particles thus produced activate macrophages, which in turn release substances resulting in loosening and osteolysis. In a complex mechanical-biological system such as total knee replacement, there can be many types of wear. Polyethylene thinning, although commonly seen, is a complex type of wear.

Persistent osteophytes have been reported to cause problems occasionally $[9,10]$. Meticulous resection of the osteophyte is an important technique to prevent postoperative discomfort in the knee. Small osteophytes can be easily missed, especially in posterior compartments. These osteophytes can cause asymmetrical abrasive wear ('Mode-2 wear' [3]) of a non-articulating polyethylene surface. Asymmetrical wear of a polyethylene bearing can alter the mechanical axis of the knee and thereby increase

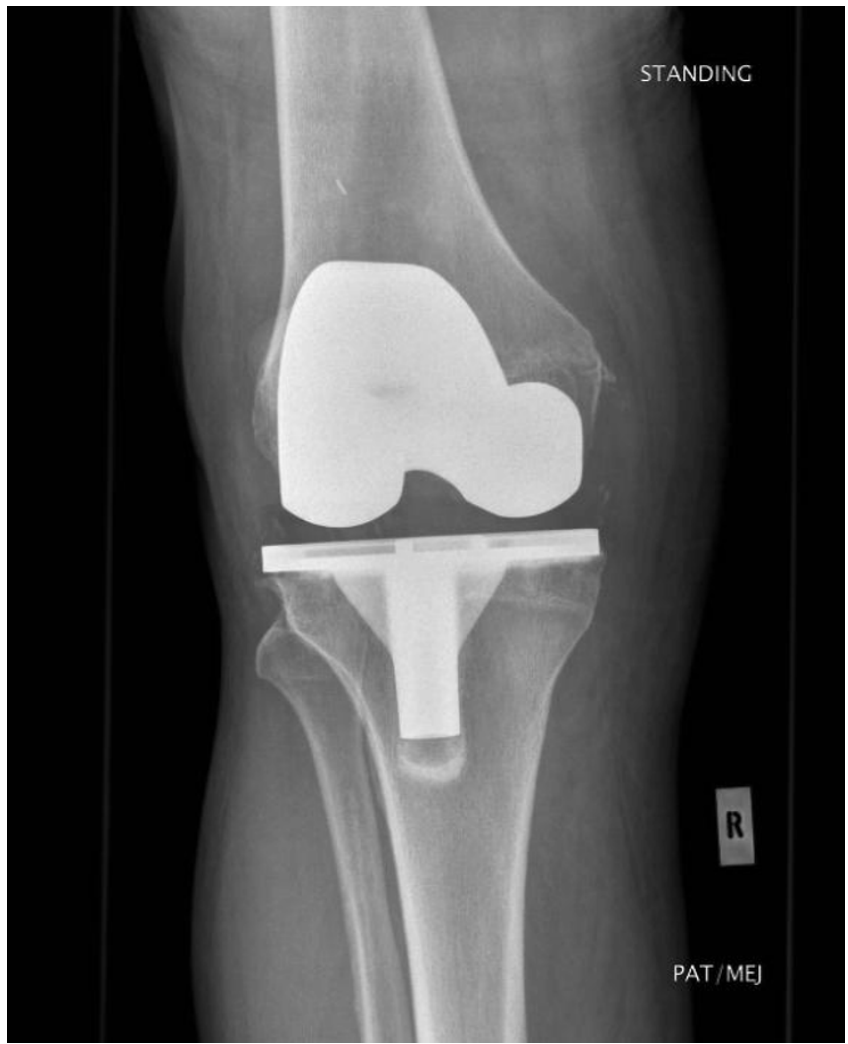

Figure 3

Radiograph post-medial femoral osteophyte excision (arrow). Tibial and femoral components are unchanged.

the rate of wear in that compartment because of the increased load $[8,11,12]$.

Friction is the resistance to movement between two surfaces in contact. Frictional torque is the force created as a result of the friction of bearing. In Mode- 2 wear, significant frictional torque can accelerate the wear process.

Osteophytes can interact with the polyethylene and surrounding soft tissues to cause a synovial reaction and wear. If left untreated, osteophytes are known to enlarge in size. Recurrent osteophytes post-excision are not uncommon [10]. Retained osteophytes have been known to cause problems but may also be asymptomatic. Therefore, there has to be a further contributing factor for this synovial reaction and wear caused by osteophytes. Some knee implant designs have slight tibial overhang as compared with the femoral component of same size [13], exposing more area of the non-articulating polyethylene surface to surrounding tissues (Figure 1 to Figure 3). Consequently, there is an increased possibility of interaction between the non-articulating polyethylene and the surrounding tissues, including any persistent osteophytes. This, in turn, accelerates abrasive polyethylene wear and 
intermittent synovitis [14]. Therefore, retained osteophytes in combination with a large surface area of nonarticulating polyethylene (as in our case, with tibial component overhang) can cause this type of synovial reaction and wear. In our patient, removal of the osteophyte, without changing the tibial implant, was sufficient to clear his symptoms. Therefore, neither of these two factors in isolation caused detrimental effects, but it is their combination which created this situation. Therefore, treatment should be directed at addressing either or both of these issues.

\section{Conclusion}

This report provides evidence that the combination of osteophyte and tibial component overhang can be detrimental after TKA. We further show that this can be resolved by addressing either or both of the detrimental factors. This report emphasises the importance of meticulous osteophyte excision and avoiding tibial component overhang during TKA.

\section{Consent}

Written informed consent was obtained from the patient for publication of this case report and accompanying images. A copy of the written consent is available for review by the Editor-in-Chief of this journal.

\section{Competing interests}

The authors declare that they have no competing interests.

\section{Authors' contributions}

MR and AP 1) both made substantial contributions to conception and design, acquisition and interpretation of the data; 2) were both involved in drafting the manuscript or in revising it critically for important intellectual content; and 3) have both given final approval of the version to be published.

\section{References}

I. Elson DW, Brenkel IJ: A conservative approach is feasible in unexplained pain after knee replacement. A selected cohort study. J Bone Joint Surg Br 2007, 89(8): 1042-1045.

2. Gonzalez MH, Mekhail AO: The failed total Inee arthroplasty: evaluation and etiology. J Am Acad Orthop Surg 2004, I 2:436-446.

3. Schmalzried TP, Callaghan JJ: A current concepts review - wear in total hip and knee replacements. J Bone Joint Surg 1999, 8I:II5-136.

4. Van Mourik JBA, Verhaar JAN, Heijboer RP, Van Kampen A: Limited value of arthroscopic evaluation and treatment of painful knee prosthesis of 27 cases. Arthroscopy 1998, I 4:877-879.

5. Jones SMG, Pinder IM, Moran CG, Malcolm AJ: Polyethylene wear in uncemented knee replacements. J Bone Joint Surg $B r$ 1992, 74:18-22.

6. Saouti R, van Royen BJ, Fortanier CM: An impinging remnant meniscus causing early polyethylene failure in total knee arthroplasty: a case report. J Med Case Reports 2007, I:48.

7. Scher DM, Paumier JC, Di Cesare PE: Pseudomeniscus following total knee arthroplasty as a cause of persistent knee pain. J Arthroplasty 1997, I 2(1): I |4- I I8.

8. Cameron HU: Tibial component wear in total knee replacement. Clin Orthop Relat Res 1994, 309:29-32.
9. Dennis DA, Channer M: Retained distal femoral osteophyte. An infrequent cause of postoperative pain following total knee arthroplasty. J Arthroplasty 1992, 7(2): 193-195.

10. Majewski M, Weining G, Friederich NF: Posterior femoral impingement causing polyethylene failure in total knee arthroplasty. J Arthroplasty 2002, I 7(4):524-526.

II. Plante-Bordeneuve P, Freeman MAR: Tibial high-density polyethylene wear in conforming tibiofemoral prostheses. J Bone Joint Surg $B r$ 1993, 75(4):630-636.

12. Wasielewski RC, Galante JO, Leighty RM, Natarajan RN, Rosenberg AG: Wear patterns on retrieved polyethylene tibial inserts and their relationship to technical considerations during total knee arthroplasty. Clin Orthop Relat Res 1994, 299:3 I-43.

13. Schai PA, Thornhill TS, Scott RD: Total knee arthroplasty with the PFC system. Results at a minimum of ten years and survivorship analysis. J Bone Joint Surg Br 1999, 8 I (3):558-559.

14. Bosco J, Benjamin J, Wallace D: Quantitative and qualitative analysis of polyethylene wear particles in synovial fluid of patients with total knee arthroplasty. A preliminary report. Clin Orthop Relat Res 1994, 309: I I-19.
Publish with Bio Med Central and every scientist can read your work free of charge

"BioMed Central will be the most significant development for disseminating the results of biomedical research in our lifetime. "

Sir Paul Nurse, Cancer Research UK

Your research papers will be:

- available free of charge to the entire biomedical community

- peer reviewed and published immediately upon acceptance

- cited in PubMed and archived on PubMed Central

- yours - you keep the copyright

Submit your manuscript here:

http://www.biomedcentral.com/info/publishing_adv.asp
BioMedcentral 